W. RUSSEll. - L'ORONge dans la banlieue de paris.

Ludovic LEGrÉ ayant commis une erreur interprétative, je l'ai relevée, non par outrecuidance, mais pour le respect dù au Cuique suum.

M. Russel a envoyé la Note suivante, dont il est donné lecture :

\title{
L'Oronge dans la banlieue de Paris;
}

PAR M. W. RUSSELL.

L’Oronge (Amanita cæsarea Scop.), ce délicieux Champignon, si recherché des habitants du midi et du centre de la France, est, comme l'on sait, assez rare dans la région parisienne. LÉveillé l'a indiquée à Verrières, d'après le peintre Redouté, ce qui a été vérifié depuis. Paclet l'a rencontrée dans la forêt de Sénart, à Ormesson, à Fontainebleau, à Meudon et à I'Isle-Adam. Ropues l'a trouvée à Versailles, Ville-d'Avray, Cernay et Rambouillet. M. Dunée l'a récoltée dans les bois des environs de Meaux et de Lagny. M. Léon Dufour l'a signalée à Champagne, près de Fontainebleau, et M. Boudier dans la forèt de Carnelle ${ }^{1}$. J'ai le plaisir d'ajouter, à la nomenclature des localités où l'on peut trouver l'Oronge, les bois des Casseaux près de Palaiseau. Ces bois sont situés sur le territoire de la commune de Villebon, au bord du plateau de Villejust, et dominent la belle vallée de l'Yvette.

L'Oronge s'y rencontre communément en plusieurs endroits, notamment au lieu dit la Basse Bourgogne, et sur les bords du ravin où coule par intermittence le ru de Batencue.

A la Bourgogne, l'Oronge est localisée dans un espace assez restreint, tandis qu'au bord du ru, elle s'observe, de part et d'autre d'un petit sentier, sur une longueur d'environ 100 mètres ; elle vit dans un terrain siliceux-argileux, au milieu des Ajones, des Bruyères et des Fougères. Les essences forestières qui prédominent sont le Chène, le Bouleau et le Charme. Pendant

1. Boudier (E.), Observations sur quelques-unes des principales espèces d'Amanites, in Bull. Soc. Mycol., 1902, p. 252. - Dufour (L.), Une nouvelle localité de l'Amanita cæsarea, in Bull. Soc. Blycol., 1901, pp. 299-301. 
l'année 1905, qui a été particulièrement chaude et humide, j'ai récolté des Oronges depuis le 31 août jusqu'au 28 septembre ${ }^{1}$. En 1906, malgré la sécheresse estivale qui a été très préjudiciable au développement de toutes les espèces de Champignons, j'ai pu recueillir la précieuse Cryptogame en assez grande abondance le 21 septembre et le 3 octobre.

M. Malinvaud, ayant remarqué que l'Oronge semble préférer les terrains siliceux, demande s'il en est toujours ainsi. M. Gagnepain dit qu'il a fait la même observation et ajoute quelques détails sur les conditions biologiques de ce Champignon dans le département de la Nièvre.

Une analyse est donnée, en séance, du travail suivant de M. Hamet :

\title{
Observations sur le genre Drosera;
}

\author{
PAR M. R. HAMET.
}

\section{Introduction.}

Ayant remarqué combien le genre Drosera, si souvent l'objet des études des physiologistes, avait été délaissé par les systématiciens, j'avais entrepris d'en rédiger une monographie. Cette étude était terminée, lorsque parut, dans le Pflanzenreich, la revision de la famille des Droséracées par M. Diess. De ce fait, mon travail faisait double emploi. J'ai cru néanmoins qu'il y aurait quelque intérèt à publier le résultat de mes observations personnelles. On s'étonnera peut-ètre de la disproportion de ces observations, dont les unes comptent presque une page, et dont les autres se réduisent à quelques lignes. La raison de cette disproportion est que je n'ai point cru devoir répéter les descriptions antérieures, me bornant à ajouter à celles-ci des éléments nouveaux, mais étant obligé parfois de les refondre entièrement, lorsqu'elles étaient trop obscures ou trop erronées.

1. Cette même année, un de mes amis, M. G. Cotrereaux, m'a com muniqué trois exemplaires d'Oronges qu'il avait trouvés dans la forêt d'Ormoy, située à 56 kilomètres au nord de Paris. 


\section{$2 \mathrm{BHL}$ Biodiversity Heritage Library}

Russell, M W . 1907. "L'Oronge dans la banlieue de Paris." Bulletin de la Société botanique de France 54, 25-26.

https://doi.org/10.1080/00378941.1907.10831222.

View This Item Online: https://www.biodiversitylibrary.org/item/8676

DOI: https://doi.org/10.1080/00378941.1907.10831222

Permalink: https://www.biodiversitylibrary.org/partpdf/160615

\section{Holding Institution}

Missouri Botanical Garden, Peter H. Raven Library

\section{Sponsored by}

Missouri Botanical Garden

\section{Copyright \& Reuse}

Copyright Status: Public domain. The BHL considers that this work is no longer under copyright protection.

This document was created from content at the Biodiversity Heritage Library, the world's largest open access digital library for biodiversity literature and archives. Visit BHL at https://www.biodiversitylibrary.org. 